\title{
$\beta$-Cyclodextrin-g-Poly (2-(dimethylamino) ethyl methacrylate) as the Stabilizer and Reductant to Prepare Colloid Silver Nanoparticles in situ
}

\author{
Jianhua Zhou ${ }^{1,2, *}$, Xianghua Zha', Xin Chen', Jianzhong Ma ${ }^{1,2}$ \\ ${ }^{1}$ College of Bioresources Chemistry and Materials Engineering, Shaanxi University of Science and Technology, Xi'an 710021, CHINA. \\ ${ }^{2}$ National Demonstration Center for Experimental Light Chemistry Engineering Education (Shaanxi University of Science and \\ Technology), Xi'an 710021, CHINA.
}

\begin{abstract}
Background: The preparation of silver nanoparticles often involves some tedious steps and extra reducing agents. PDMAEMA and $\beta-C D$ can act as the reducing and stabilizing agents for the preparation of silver nanoparticles without any external reducing agent. Methods: $\beta$-Cyclodextrin-g-Poly (2-(dimethylamino) ethylmethacrylate) as the stabilizer and reductant to prepare colloid silver nanoparticles in situ. Such an approach greatly simplified the preparation and purification of silver nanoparticles. Results: The graft yield of $\beta$-CD-g-PDMAEMA increased with the increase of amount of DMAEMA.Ag nanoparticles was obtained under neutral or slightly alkaline environment. The intensity of surface plasmon resonance peak of $\mathrm{Ag}$ nanoparticles increased as the concentration of $\beta$-CD-g-PDMAEM and silver nitrate increased. In addition, the $\mathrm{Ag}$ nanoparticles were in the form of spherical particles observed by transmission electron microscopy (TEM). The FTIR spectrum of nanocomposite showed that coordination existed between the silver nanoparticles and tertiary amino groups of PDMAEMA segments. Conclusion: Silver nanoparticles were successfully prepared by in situ synthetic method, using $\beta-C D-g-$ PDMAEMA as both reductant and stabilizer. It can be envisioned that the theroresponsive silver nanocomposite could find applications in biomedical feld.

Key words: Silver Nanoparticles, Poly(2-(Dimethyl amino) Ethyl Methacrylate), $\beta$-Cyclodextrin, in situ Method.
\end{abstract}

\section{INTRODUCTION}

The nano-scale materials are considered as one of the interesting topics in fundamental science owing to their attractive properties in optical, electrical, magnetic and other fields. ${ }^{1-4}$ Meanwhile, nano-scale materials lead to a progressive impetus to the development of their novel preparation methods. The development of simple and versatile methods for the preparation of nanoparticles in a size- or shape-selected and controlled manner is an important and challenging task. ${ }^{5-6}$ Silver nanoparticles, as a significant member of the noble metal nanoparticles, have recently received much attention due to their various potential applications in catalysts. ${ }^{7-8}$ chemical sensors, ${ }^{9-11}$ antibacterial materials, ${ }^{12-16}$ biomol- ecule detection, ${ }^{17}$ and so forth. Traditionally, the preparation of silver nanoparticles often involves some tedious steps and extra reducing agents including sodium borobydride $\left(\mathrm{NaHB}_{4}\right),{ }^{17}$ sodium formaldehyde sulfoxylate (SFS), ${ }^{18}$ and solvents like $\mathrm{N}, \mathrm{N}$-dimethylformamide (DMF), ${ }^{19}$ acetone,${ }^{20}$ etc. In addition, $\mathrm{X}$-ray and UV irradiation are also utilized as the alternative to reduce the silver ion. Recently, some reports have demonstrated that PDMAEMA can act as both reducing agent and stabilizer simultaneously in the formation of gold nanoparticles, ${ }^{21-24}$ based on the fact that Poly (2-(dimethylamino) ethyl methacrylate) (PDMAEMA) is a hydrophilic polymer with temperature and $\mathrm{pH}$ sensitivities, excellent biocompatibility, and
Submission Date: 18-01-2017; Revision Date: 02-03-2017; Accepted Date: 05-05-2017

DOI: $10.5530 /$ ijper.51.4.83 Correspondence: Jianhua Zhou,

College of Bioresources Chemistry and Materials Engineering, Shaanxi University of Science and Technology, Xi'an 710021, CHINA

Tel.: +86-029-86132559-609; Fax: +86-029-86132559-603 E-mail: zhoujianh@21cn.com

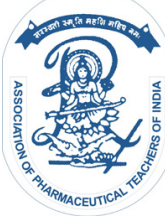

www.ijper.org 
a well-studied environmentally responsive polymer. ${ }^{25}$ Such an approach greatly simplified the preparation and purification of gold nanoparticles. In contrast, very few papers have been published to date on the preparation of Ag nanoparticles using PDMAEMA as a reducing agent. Steigerwald et al found that copolymers containing PDMAEMA block can reduce $\mathrm{Ag}^{+}$to $\mathrm{Ag}^{0}$ without any external reducing agent. ${ }^{26}$ Cyclodextrin has been a topic of substantial interest owing to its attractive properties such as non-toxic, biodegradability, and biocompatibility. It has been widely used in various industries including pharmaceuticals, cosmetics, food manufacturing, chromatography and textile, etc. ${ }^{27-}$ ${ }^{30}$ In the $\beta$-cyclodextrin( $\beta$-CD) molecules, the secondary hydroxyl groups are located on the wider edge of the cone while the primary hydroxyl groups are located on the narrow side. Therefore, cyclodextrin molecules have a special structure with the external hydrophilicity and internal bydrophobicity. Due to this special feature, aminated $\beta-C D$ can act as the reducing and stabilizing agent for the preparation of silver nanoparticles from $\mathrm{AgNO}_{3}{ }^{31}$ This is a very promising method in preparing environment friendly silver nanoparticles with excellent properties such as antibacterial and antistatic. However, it is usually necessary to add an organic solvent or use the microwave heating because $\beta$-CD has a low solubility in the water at room temperature. In order to avoid environmental pollution caused by organic solvent, some hydrophilic polymers were grafted to $\beta-C D$ molecules to improve the solubility of $\beta-C D$ in an aqueous medium. For example, $\beta$-cyclodextrin- $g$-poly (acrylic acid) and aminated $\beta$-cyclodextrinwere successfully prepared in aqueous solution. ${ }^{31}$

In the present study, Ag nanoparticles were successfully prepared using $\beta$-cyclodextrin-g-poly (2-(dimethylamino) ethyl methacrylate) ( $\beta$-CD- $g$-PDMAEMA) as reducing and stabilizing agent in aqueous solution. $\beta$-CD- $g$-PDMAEMA was synthesized by graft polymerization of 2-(dimethylamino) ethyl methacrylate onto $\beta$-cyclodextrin. And the resulting $\beta$-CD- $g$-PDMAEMA and $\mathrm{Ag}$ nanocomposite were characterized by fourier transform infrared spectrum (FTIR), transmission electron microscopy (TEM), ultraviolet-visible (UV-vis) spectrum.

\section{MATERIALS AND METHODS}

\section{Materials}

$\beta$-cyclodextrin $(\beta-C D)$ was obtained from Tianjin Kemiou Chemical Reagent Company. 2-(dimethylamino) ethyl methacrylate (DMAEMA) purchased from Jiangsu Feixiang Chemical Company passed through a basic alumina column to remove the inhibitor. Potassium persulphate (KPS) was produced by Tianjin Tianli Chemical Reagents Ltd. Acetone, ethyl alcohol and silver nitrate were of analytical reagent grade available from Sinopharm Chemical Reagent Company.

\section{Synthesis of $\beta$-cyclodextrin-g-poly (2-(dimethylamino) ethyl methacrylate) ( $\beta-C D-g-$ PDMAEMA)}

$\beta-C D(5.00 \mathrm{~g})$ and $25 \mathrm{~mL}$ deionized water were charged to a three-neck flask. Then 2-(dimethylamino) ethyl methacrylate (DMAEMA) (2.50 g) was added to the solution, and the mixture was stirred at the rate of $250 \mathrm{rpm} / \mathrm{min}$. Initiator KPS $(0.17 \mathrm{~g})$ solubilized by deionized water ( 5 $\mathrm{mL}$ ) is added dropwise to the flask at $65^{\circ} \mathrm{C}$ for about $30 \mathrm{~min}$. After that, the reaction has been carried out continuously for another $120 \mathrm{~min}$ at $65^{\circ} \mathrm{C}$. The crude productwas dissolved in acetone, precipitated intoethanol three times, and dried at $50^{\circ} \mathrm{C}$ for $24 \mathrm{~h}$ in a vacuum to give a white material.

\section{In situ preparation of $\beta$-CD-g-PDMAEMA/Ag hybrid nanocomposite}

$5 \mathrm{~mL}$ of $\mathrm{AgNO}_{3}$ aqueous solution $(0.005 \mathrm{~mol} / \mathrm{L})$ was dropped into $20 \mathrm{~mL}$ aqueous solution of $\beta-\mathrm{CD}-g_{-}$ PDMAEMA under vigorous stirring. Then it has been stirred for $24 \mathrm{~h}$ at room temperature in the dark.

\section{Characterization}

Fourier transform infrared (FTIR) spectra were obtained on a VERTE70 infrared spectrometer. Transmission Electron Microscopy (TEM) measurement for micelles was performed on a JEM-100SX instrument at a voltage of $120 \mathrm{kV}$. A drop of the sample solution was cast on a carbon-coated copper grid, followed by drying at room temperature. UV spectra were performed on a TU-1900 Double Bean UV-vis spectrophotometer.

\section{RESULTS AND DISCUSSION}

\section{Synthesis of $\beta$-cyclodextrin-g-poly (2-(dimethylamino) ethyl methacrylate)}

The synthesis route for $\beta$-cyclodextrin-g-poly (2-(dimethylamino) ethyl methacrylate) ( $\beta$-CD- $g$-PDMAEMA) is outlined in Scheme 1. The grafting DMAEMA onto $\beta$-CD involved in the following steps: (1) the generation of reactive sites on $\beta$-CD backbone under the action of potassium persulphate initiator; (2) the addition of DMAEMA molecules to $\beta$-CD free radical to form the graft chain. Since the $\beta$-CD- $g$-PDMAEMA will be used as the reducing and stabilizing agent in the preparation of the Ag nanoparticles. Therefore, it is important to investigate the graft yield of DMAEMA molecules to 
$\beta$-CD. The graft yield expresses the increase in weight of $\beta$-CD divided by its original weight. The relationship between DMAEMA amount and the graft yield is shown in Figure 1. As is evident, the graft yield substantially increases with the increase of DMAEMA amount up to $140 \%$. The structure of $\beta$-CD- $g$-PDMAEMA was characterized by FTIR. As shown in Figure 2, the $\mathrm{OH}$ stretching absorption displays a typical broad peak at $3350 \mathrm{~cm}^{-1}$, which is attributed to hydroxy groups in $\beta$-CD. The bands at $2924 \mathrm{~cm}^{-1}$ can be assigned to characteristic absorption peak of methylene group $\left(-\mathrm{CH}_{2}\right)$. The characteristic peaks at $1078 \mathrm{~cm}^{-1}$ and $1025 \mathrm{~cm}^{-1}$ corresponded to the coupled vibrations of $\mathrm{C}-\mathrm{C} / \mathrm{C}-\mathrm{O}$ and stretching vibration of $\mathrm{C}-\mathrm{O}-\mathrm{C}$ within $\beta-\mathrm{CD}$ cavity, respectively. It is the evidence for glucose linkages in $\beta$-CD structure. ${ }^{32}$ The characteristic stretching vibration peak of $\mathrm{C}=\mathrm{O}$ and $\mathrm{C}-\mathrm{N}$ of DMAEMA appears at $1729 \mathrm{~cm}^{-1}$ and $1266 \mathrm{~cm}^{-1}$, respectively. Therefore, FTIR result demonstrates that $\beta$-CD- $g$-PDMAEMA has been obtained.

\section{In situ preparation of $\beta$-CD-g-PDMAEMA/Ag hybrid nanocomposite}

The aforementioned $\beta$-CD- $g$-PDMAEMA was used to prepare Ag nanoparticles. $\beta$-CD-g-PDMAEMA performed dual role: reducing agent and stabilizing agent during the preparation of Ag nanoparticles. The factors that governed the preparation of Ag nanoparticles were studied, such as concentration of $\beta$-CD- $g$-PDMAEMA, silver nitrate concentration, and $\mathrm{pH}$ values. The formation of Ag nanoparticles was determined by UV-visible absorption spectra and transmission electron microscopy (TEM).

\section{Effect of concentration of $\beta$-CD- $g$-PDMAEMA on the preparation of $\mathrm{Ag}$ nanoparticles}

In our experiment, $\beta$-CD- $g$-PDMAEMA using 50\% DMAEMA based on the $\beta$-CD weight was used at different concentrations for the preparation of silver nanoparticles. Figure 3 shows the effect of the concentration of $\beta$-CD- $g$-PDMAEMA in the range from $0.0012 \mathrm{mg} / \mathrm{L}$ to $0.0300 \mathrm{mg} / \mathrm{L}$ on the UV-vis spectra of $\mathrm{Ag}$ nanoparticles. It can be observed that the intensity of surface plasmon resonance peak of $\mathrm{Ag}$ nanoparticles increases from 0.023 to 1.636 at around $422 \mathrm{~nm}$ with the increment of $\beta$-CD- $g$-PDMAEMA concentration from $0.0012 \mathrm{mg} / \mathrm{L}$ to $0.0300 \mathrm{mg} / \mathrm{L}$, indicating the increase of the concentration of $\mathrm{Ag}$ nanoparticles. It is thought that when $\mathrm{AgNO}_{3}$ solution was added to $\beta$-CD$g$-PDMAEMA aqueous solution, the nitrogen atom in the tertiary amino groups lost one electron to form the oxidized tertiary amino groups, and $\mathrm{Ag}^{+}$acquired the electron to be reduced into $\mathrm{Ag}^{0}$. Therefore, the amount

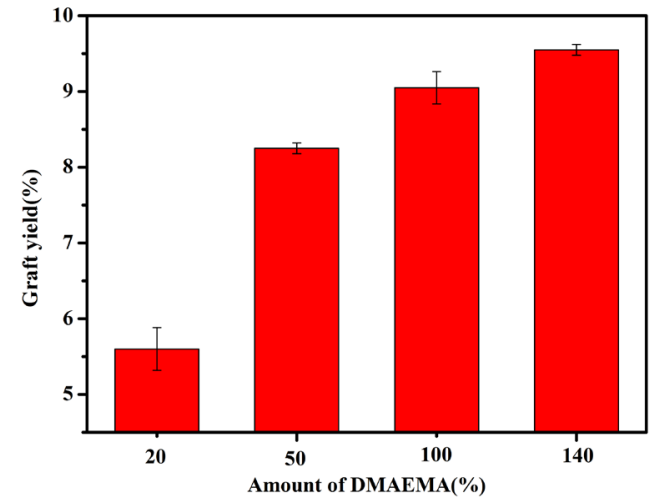

Figure 1: Effect of the amount of DMAEMA on the graft yield.

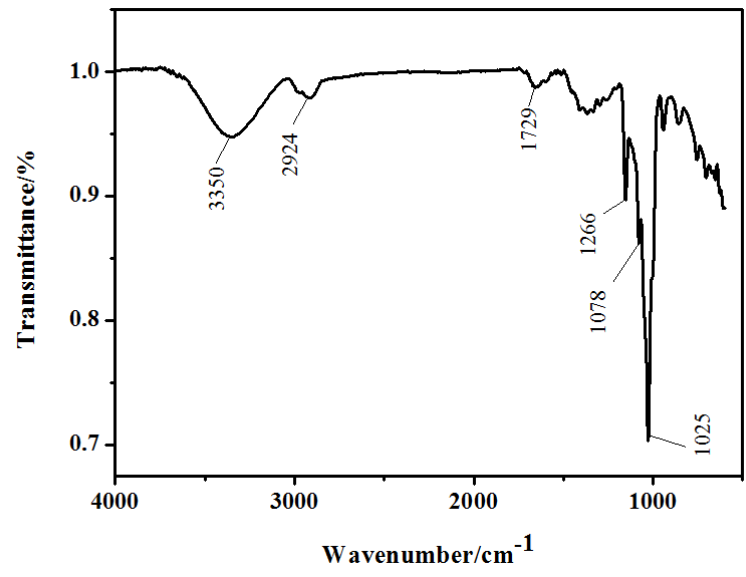

Figure 2: FTIR spectrum of $\beta$-CD-g-PDMAEMA.

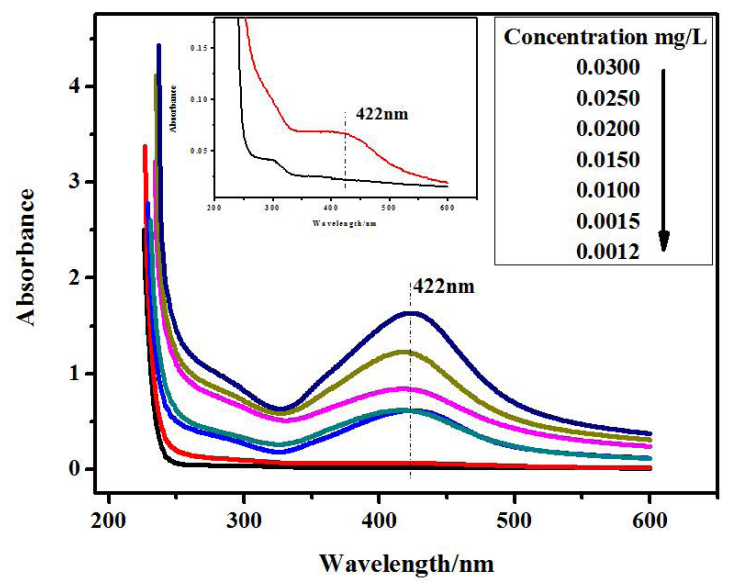

Figure 3: UV-vis spectra of Ag nanoparticles at various concentrations of $\beta-C D-g-P D M A E M A$.

of Ag nanoparticles increases along with the increase of $\beta$-CD- $g$-PDMAEMA concentration.

\section{Effect of concentration of silver nitrate on the preparation of $\mathrm{Ag}$ nanoparticles}

Silver nitrate is the precursor of Ag nanoparticles during the preparation of $\mathrm{Ag}$ nanoparticles. Silver nitrate was 
used at different concentrations along with constant $\beta$-CD-g-PDMAEMA concentration and $\mathrm{pH}$ value for preparation of Ag nanoparticles. Figure 4 (a) shows the effect of the silver nitrate concentration on the UV-vis spectra of $\beta$-CD-g-PDMAEMA/Ag nanocomposite solution. The intensity of surface plasmon resonance peak of Ag nanoparticles increases along with the increase of silver nitrate concentration. In addition, it can be seen that the surface plasmon resonance peak $\left(\lambda_{\max }\right)$ shows the red shift of the wavelength with the increase of the concentration of silver nitrate, suggesting that the average size of the Ag nanoparticles becomes bigger. Abou-Okeil ${ }^{33}$ also reported a similar variation tendency. Figure 4 (b, c) shows TEM micrographs of Ag nanoparticles, and Figure 4 (d) shows particles size of the silver nanoparticles with different concentrations of silver nitrate. The morphologies of the nanoparticles are spherical. When silver nitrate concentration is $5 \mathrm{mmol} / \mathrm{L}$, the average size of the Ag nanoparticles is $21.8 \mathrm{~nm}$ and was nearly uniform in their size dispersion, and is separated from one another. However, when the concentration of silver nitrate is $10 \mathrm{mmol} / \mathrm{L}$, the average size of the Ag nanoparticles is $45 \mathrm{~nm}$. The increase of silver nitrate concentration causes the increase of the quantity of silver nitrate in the reaction system, so supersaturation degree of the nucleus in the $\beta$-CD- $g$-PDMAEMA is too high, more $\mathrm{Ag}^{0}$ particles from $\mathrm{Ag}^{+}$reduction aggregate easily with each other, resulting in the bigger particle size of $\mathrm{Ag}$ nanoparticles. Therefore, the size analysis result from TEM images is consistent with that of UV-vis absorption characteristics.

\section{Effect of PDMAEMA chain length on the preparation of $\mathrm{Ag}$ nanoparticles}

PDMAEMA can provide a suitable environment for the reduction of silver ion through the amine groups. ${ }^{25}$ In our experiments, copolymers containing different PDMAEMA chain length were firstly synthesized using DMAEMA monomer at concentrations of $20 \%, 50 \%$, $100 \%$, and $140 \%$ based on the weight of $\beta-C D$, and the obtained copolymers were used for the preparation of $\mathrm{Ag}$ nanoparticles. Figure 5(A-D) shows the TEM images of $\mathrm{Ag}$ nanoparticles at different concentration of DMAEMA. It was found that the particles size of $\mathrm{Ag}$ nanoparticle increases from 21.1 to $48.3 \mathrm{~nm}$ (Figure 5E) and size distribution of $\mathrm{Ag}$ nanoparticle becomes wide as the concentration of DMAEMA based on the $\beta$-CD weight increases from $20 \%$ to $140 \%$.

This phenomenon can be explained by the fact that the amine group number increases with the increase of DMAEMA concentration, and the reduction ability of $\beta$-CD- $g$-PDMAEMA also increases. More and more $\mathrm{Ag}^{0}$

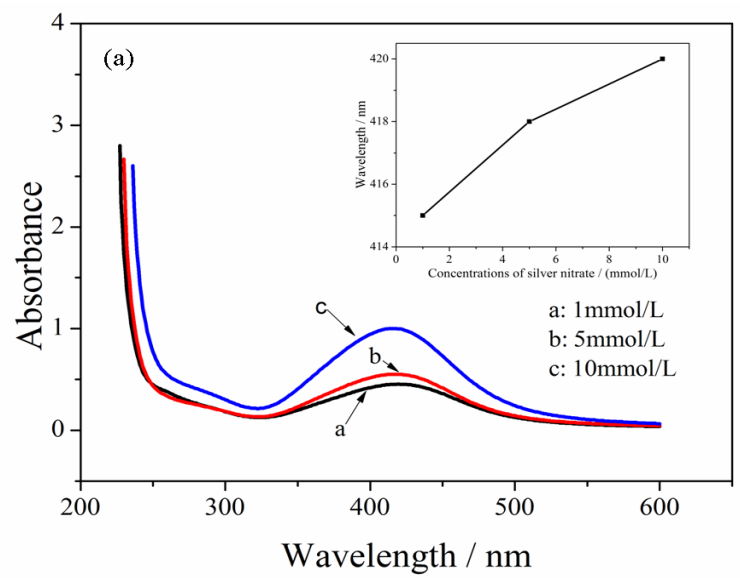

Figure 4: (a) UV-vis spectra of Ag nanoparticles at various concentrations of silver nitrate.

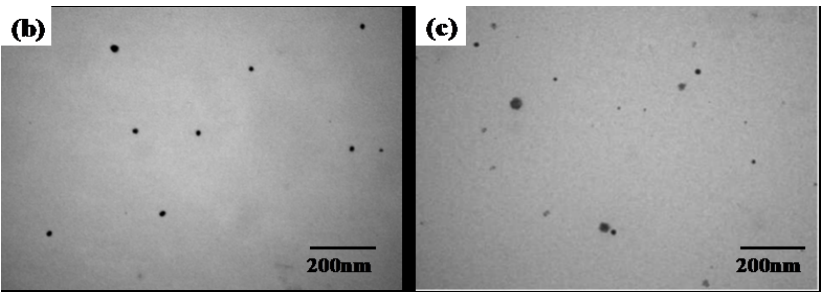

Figure 4(b,c): TEM images of Ag nanoparticles prepared with different silver nitrate concentrations (b) $5 \mathrm{mmol} / \mathrm{L}$, (c) $10 \mathrm{mmol} / \mathrm{L}$.

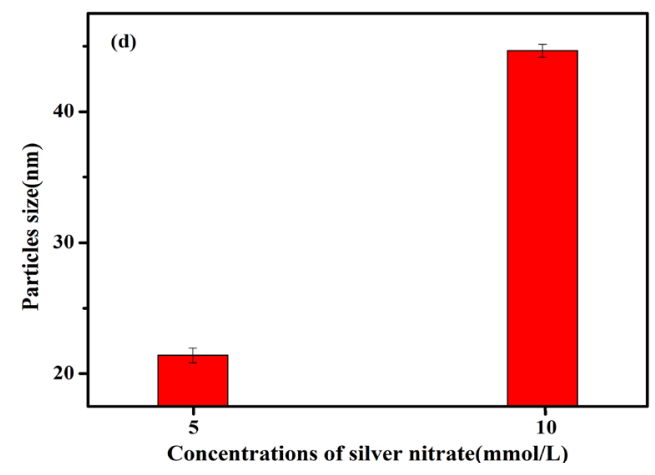

Figure 4: (d) Particles size of Ag nanoparticles with different concentrations of silver nitrate.

particles have been formed by the reduction of amine groups. In the case of nanoparticles, agglomeration and precipitation occurs very easily due to their collision with each other. Finally, Ag nanoparticles present wider particle size distribution, and bigger particle size. Figure 5(F) shows the UV-vis spectra of Ag nanoparticles at different concentration of DMAEMA based on the $\beta$-CD weight increases from $20 \%$ to $140 \%$. The intensity of surface plasmon resonance peak of Ag nanoparticles increases at around $421 \mathrm{~nm}$ with the increase of PDMAEMA chain length up to DMAEMA concentration of $100 \%$ based on the $\beta$-CD weight. However, 


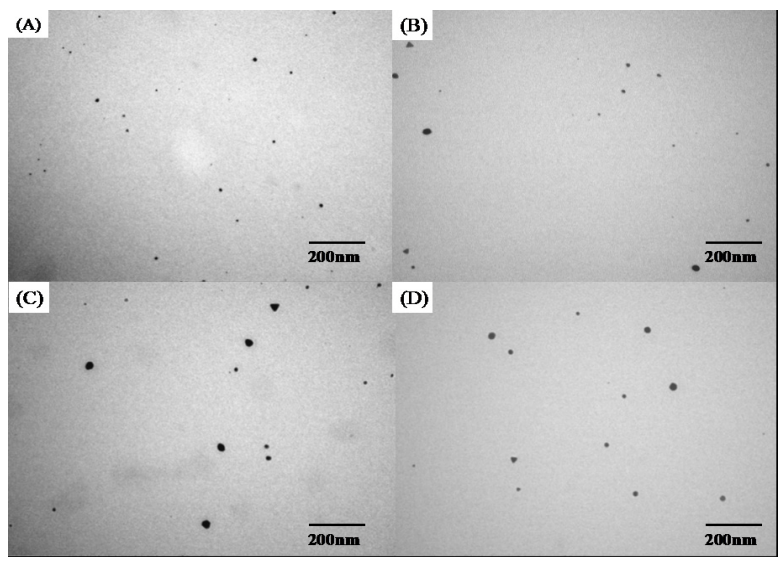

Figure 5: (A-D) TEM images of Ag nanoparticles prepared with different concentration of DMAEMA (A) $20 \%$; (B) $50 \%$; (C) $100 \%$; (D) $140 \%$ based on the $\beta-C D$ weight.

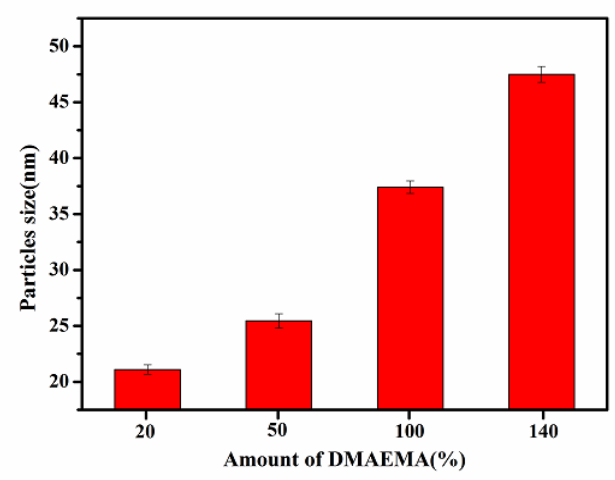

Figure 5: (E) Particles size of Ag nanoparticles with different concentration of DMAEMA.

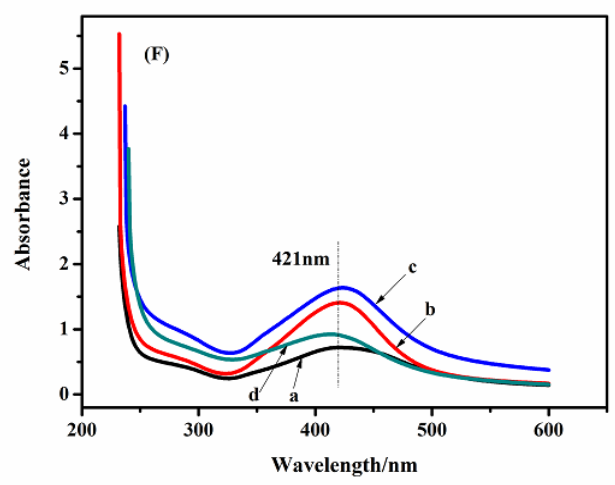

Figure 5: (F) UV-vis spectra of Ag nanoparticles at various concentrations of DMAEMA (a) $20 \%$; (b) $50 \%$; (c) $100 \%$; (d) $140 \%$ based on the $\beta-C D$ weight.

when the concentration of DMAEMA is $140 \%$ based on the $\beta$-CD weight, the intensity of surface plasmon resonance peak of $\mathrm{Ag}$ nanoparticles decreases. This is because the agglomeration and precipitation of $\mathrm{Ag}$ nanoparticles causes the low absorbance at the surface plasmon resonance peak $\left(\lambda_{\text {max }}\right)$.

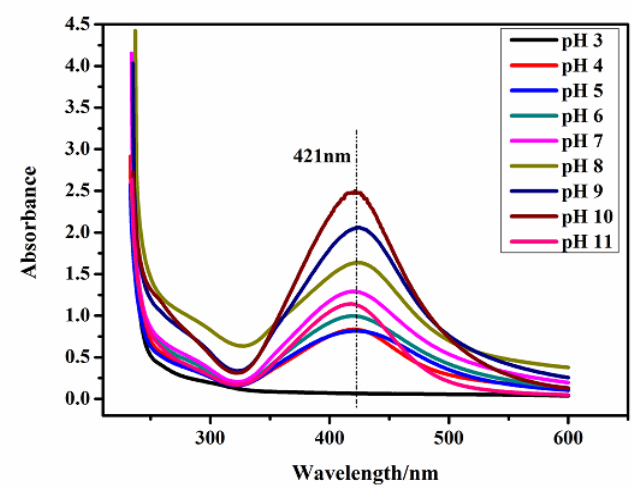

Figure 6: UV-vis spectra of Ag nanoparticles prepared with different $\mathrm{pH}$ value.

\section{Effect of $\mathrm{pH}$ on the preparation of $\mathrm{Ag}$ nanoparticles}

PDMAEMA has a $\mathrm{pH}$-responsive property due to the tertiary amine groups. $\mathrm{s}^{33}$ Therefore, $\mathrm{pH}$ is a very important factor in the preparation of $\mathrm{Ag}$ nanoparticles using $\beta$-CD-g-PDMAEM as reducing and stabilizing agent. Figure 6 shows the UV-vis spectra of Ag nanoparticles prepared at different $\mathrm{pH}$ values adjusted by $\mathrm{NaOH}$ or $\mathrm{HNO}_{3}$. At $\mathrm{pH}$ 3, the system is a strong acidic environment, and the tertiary ammonium groups of PDMAEMA segments can easily form quaternary ammonium salt, which can inhibit the reduction reaction. Therefore, the surface plasmon peak of Ag nanoparticles can't be observed at around $421 \mathrm{~nm}$. The intensity of surface plasmon resonance peak of Ag nanoparticles increases at around $421 \mathrm{~nm}$ along with the increase of $\mathrm{pH}$ value from $\mathrm{pH} 3$ to $\mathrm{pH} 10$. However, at $\mathrm{pH} 11$, the intensity of plasmon resonance peak of $\mathrm{Ag}$ nanoparticles decreases, meanwhile, the silver colloid is unstable. On the other hand, silver ion easily form silver hydroxide at the strong alkaline condition, silver hydroxide will partially decompose, resulting in a complex product system. Therefore, the strong acidic and alkaline conditions are harmful for the formation of nano-sized silver particles.

\section{FTIR study of $\beta$-CD-g-PDMAEMA/Ag nanocomposite}

The interactions between $\beta$-CD-g-PDMAEMA and the silver nanoparticles were studied by FTIR. Figure 7 shows the FTIR spectra of $\beta$-CD-g-PDMAEMA (a) and $\beta$-CD- $g$-PDMAEMA/Ag nanocomposite (b). The $\mathrm{C}-\mathrm{N}$ stretching bands at $1266 \mathrm{~cm}^{-1}$ in Figure $7 \mathrm{a}$ shifts to $1269 \mathrm{~cm}^{-1}$ in Figure $7 \mathrm{~b}$ after PDMAEMA segments react with $\mathrm{Ag}^{+}$. This change indicates that coordination exists between the silver ions and tertiary amino groups of PDMAEMA segments. An observation of the spectra shows that the $\mathrm{C}=\mathrm{O}$ stretching peak at $1729 \mathrm{~cm}^{-1}$ is 


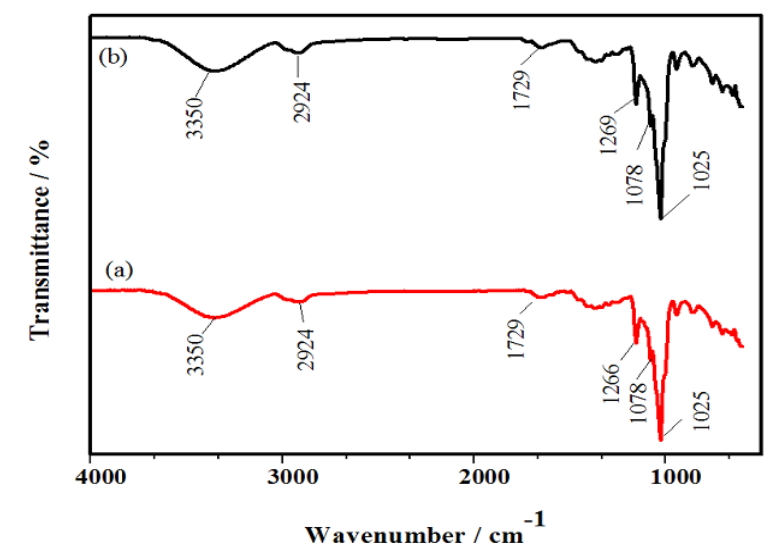

Figure 7: FTIR spectra of $\beta$-CD-g-PDMAEMA (a) and $\beta-C D-g-$ PDMAEMAAg nanocomposite (b).

hardly changed after the adsorption of PDMAEMA segments on the silver nanoparticles. It is suggested that the coordination of silver ions with tertiary amino groups is more favorable than that with the $\mathrm{C}=\mathrm{O}$ due to the stronger interaction of the tertiary nitrogen/silver pair in comparison with that of the $\mathrm{C}=\mathrm{O} /$ silver pair. Therefore, the strong coordination between the tertiary amino groups and the Ag nanoparticles resulted in the stable $\beta$-CD-g-PDMAEMA/Ag nanocomposites.

\section{Formation mechanism of silver nanoparticles}

On the basis of the above study results, the schematic procedure for the preparation of the $\beta-C D-g-$ PDMAEMA / Ag nanocomposites is demonstrated in Scheme 2. When $\mathrm{AgNO}_{3}$ solution is added to the aqueous solution of $\beta$-CD- $g$-PDMAEMA, $\mathrm{Ag}^{+}$is complexed with elector-donating centers, i.e. tertiary nitrogen in PDMAEMA segments, due to the strong coordinating interaction among them, leading to homogeneous distribution of $\mathrm{Ag}^{+}$in the polymer. The uncomplexed tertiary amine groups in the PDMAEMA segments exhibit strong reducing ability. ${ }^{26,34}$ The nitrogen atom in the tertiary amino groups loses one electron to form the oxidized tertiary amino groups, and $\mathrm{Ag}^{+}$requires the electron to be reduced into Ag, followed by nucleation and growth to silver nanoparticles. Meanwhile, the complexation of silver ions to hydroxyl groups of $\beta$-CD accelerates the reduction process by the hemiacetal groups and secondary alcoholic groups. Moreover, PDMAEMA segments and cone-shaped $\beta-C D$ can provide both the coordination bond and steric stabilization to the Ag nanoparticles in colloidal solution.

\section{CONCLUSION}

In summary, silver nanoparticles were successfully prepared by in situ synthetic method, using $\beta-C D-g-$ PDMAEMA as both reductant and stabilizer. The

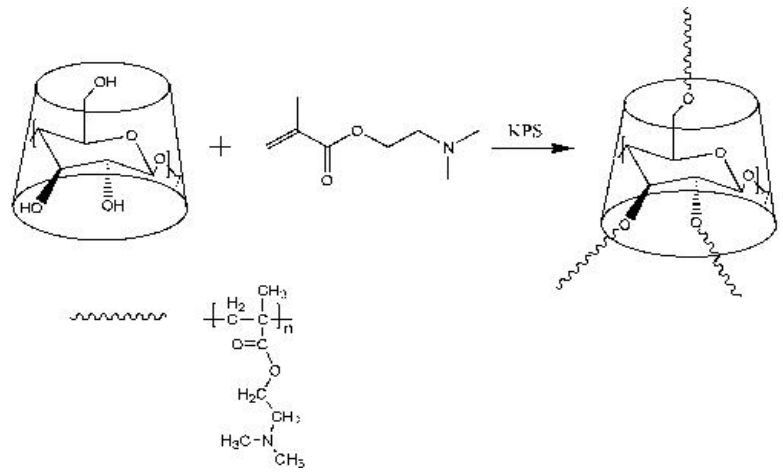

Scheme 1: Synthetic scheme of $\beta$-CD-g-PDMAEMA.

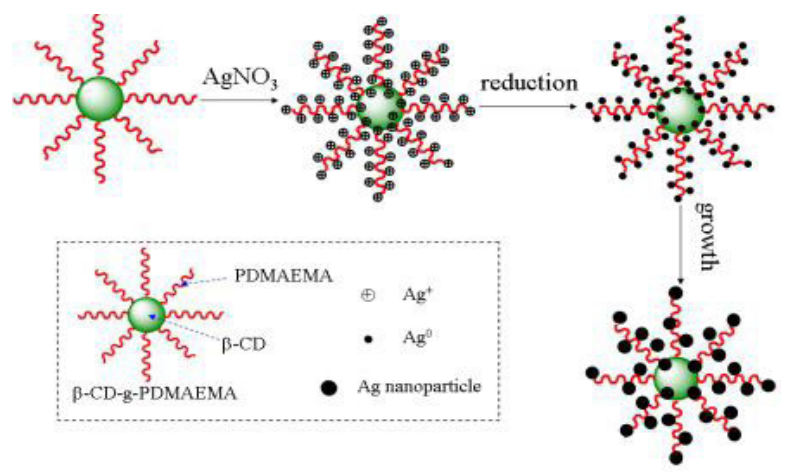

Scheme 2: Schematic procedure for the preparation of the $\beta$-CD-g-PDMAEMA/Ag nanocomposite.

graft yield of $\beta$-CD- $g$-PDMAEMA increased with the increase of amount of DMAEMA. The silver nanoparticles were monitored via UV-vis spectral analysis, and the surface plasmon resonance peak of Ag nanoparticles increased when the concentration of $\beta-\mathrm{CD}-g$ PDMAEM and silver nitrate increased. Moreover, $\mathrm{pH}$ is a crucial role in the preparation of Ag nanoparticles, and the optimal synthetic condition of $\mathrm{Ag}$ nanoparticles was obtained under neutral or slightly alkaline environment and the Ag nanoparticles had a significant plasmon resonance peak around $421 \mathrm{~nm}$. Meanwhile, TEM image signified that the silver nanoparticles were spherical shape. The FTIR spectrum of nanocomposite showed that coordination existed between the silver nanoparticles and tertiary amino groups of PDMAEMA segments. It can be envisioned that The thermoresponsive silver nanocomposite could find applications in biomedical field.

\section{ACKNOWLEDGMENT}

This work was supported by the Industrialization Cultivation Item of Shaanxi Province Educational Department(No. 16JF006), the National Natural Science Fund of CHINA (No. 21206088). 


\section{CONFLICT OF INTEREST}

The authors declare no conflict of interest.

\section{ABBREVIATION USED}

\section{प-CD-g-PDMAEMA:}

$\beta$-cyclodextrin-g-poly (2(dimethylamino) ethyl methacrylate); DMAEMA: 2-(dimethylamino) ethyl methacrylate; TEM: transmission electron microscopy; FTIR: Fourier transform infrared; प-CD: $\beta$-Cyclodextrin; $\mathrm{NaHB}_{4}$ : sodium borohydride; SFS: sodium formaldehyde sulfoxylate; DMF: N, N-dimethylformamide; UV-vis: ultraviolet-visible; KPS: Potassium persulphate.

\section{REFERENCES}

1. Linic S, Aslam U, Boerigter C, Morabito M. Photochemical transformations on plasmonic metal nanoparticles. Nat Mater. 2015;14(6):567-76. https://doi. org/10.1038/nmat4281; PMid:25990912.

2. Gole B, Sanyal U, Mukherjee PS. A smart approach to achieve an exceptionally high loading of metal nanoparticles supported by functionalized extended frameworks for efficient catalysis. Chem Commun. 2015;51(23):4872-5. https://doi.org/10.1039/C4CC09228G.

3. Palza H. Antimicrobial polymers with metal nanoparticles. Int $\mathrm{J}$ Mol Sci. 2015;16(1):2099-116. https://doi.org/10.3390/ijms16012099; PMid:25607734 PMCid:PMC4307351.

4. Rai M, Ingle AP, Birla S, Yadav A. Strategic role of selected noble metal nanoparticles in medicine. Crit Rev Microbiol. 2015;1-24. https://doi. org/10.3109/1040841X.2015.1018131; PMid:26089024.

5. Daima HK, Selvakannan PR, Kandjani AE, Shukla R, Bhargava SK, Bansal V. Synergistic influence of polyoxometalate surface corona towards enhancing the antibacterial performance of tyrosine-capped Ag nanoparticles. Nanoscale 2014;6(2):758-65. https://doi.org/10.1039/C3NR03806H ; PMid:24165753.

6. Choudhury A. Polyaniline/silver nanocomposites: Dielectric properties and ethanol vapour sensitivity. Sensor. Actuat B Chem. 2009;138(1):318-25. https://doi.org/10.1016/j.snb.2009.01.019.

7. Edison TNJI, Lee YR, Sethuraman MG. Green synthesis of silver nanoparticles using Terminalia cuneata and its catalytic action in reduction of direct yellow-12 dye. Spectrochim. Acta A. 2016;161:122-9. https://doi. org/10.1016/j.saa.2016.02.044 ; PMid:26967513.

8. Bindhu MR, Umadevi M. Antibacterial and catalytic activities of green synthesized silver nanoparticles. Spectrochim. Acta A. 2015;135:373-8. https://doi.org/10.1016/j.saa.2014.07.045 PMid:25093965

9. Nantaphol S, Chailapakul O, Siangproh W. Sensitive and selective electrochemical sensor using silver nanoparticles modified glassy carbon electrode for determination of cholesterol in bovine serum. Sensor Actuat B. 2015;207:193-8. https://doi.org/10.1016/j.snb.2014.10.041.

10. Schmidl G, Dellith J, Schneidewind H, Zopf D, Stranik O, Gawlik A, et al. Formation and characterization of silver nanoparticles embedded in optical transparent materials for plasmonic sensor surfaces. Mat Sci Eng B-Solid. 2015;193:207-16. https://doi.org/10.1016/j.mseb.2014.12.001

11. Ferreira DCM, Giordano GF, Soares CCSP, Oliveira JFA, Mendes RK. Optical paper-based sensor for ascorbic acid quantification using silver nanoparticles. Talanta. 2015;141:188-94. https://doi.org/10.1016/j. talanta.2015.03.067 ; PMid:25966401

12. Logeswari P, Silambarasan S, Abraham J. Synthesis of silver nanoparticles using plants extract and analysis of their antimicrobial property. J Saudi Chem. Soc. 2015;19(3):311-7.

13. Ishihara $M$, Nguyen $V Q$, Mori $Y$, Nakamura $S$, Hattori $H$. Adsorption of silver nanoparticles onto different surface structures of chitin/chitosan and correlations with antimicrobial activities. Int J Mol Sci. 2015;16(6):13973-88. https://doi.org/10.3390/ijms160613973; PMid:26096004 PMCid:PMC4490534.

14. Rajakannu S, Shankar S, Perumal S. Biosynthesis of silver nanoparticles using garcinia mangostana fruit extract and their antibacterial, antioxidant activity. Int J Curr Microbiol App Sci. 2015;4(1):944-952.
15. Shameli K, Ahmad MB, Al-Mulla EAJ, Shabanzadeh P, Bagneri S. Antibacterial effect of silver nanoparticles on talc composites. Res. Chem. Intermediat. 2015;41(1):251-63. https://doi.org/10.1007/s11164-013-1188-y.

16. Franci G, Falanga A, Galdiero S, Palomba L, Rai M, Morelli G, et al. Silver nanoparticles as potential antibacterial agents. Molecules. 2015;20(5):8856-74. https://doi.org/10.3390/molecules20058856 ; PMid:25993417.

17. Li YT, Smith AE, Lokitz BS. In situ formation of gold- "decorated" vesicles from a RAFT-synthesized, thermally responsive block copolymer. Macromolecules. 2007;40(24):8524-6. https://doi.org/10.1021/ma071488s.

18. Loftsson T, Masson M. Cyclodextrins in topical drug formulations: theory and practice. Int J Pharm. 2001;225(1):15-30. https://doi.org/10.1016/S03785173(01)00761-X.

19. Manno D, Filippo E, Di Giulio M, Serra A. Synthesis and characterization of starch-stabilized Ag nanostructures for sensors applications. J Non-Cryst Solids. 2008;354(52):5515-20. https://doi.org/10.1016/j.jnoncrysol.2008.04.059.

20. Khanna PK, Singh N, Charan S, Subbarao VVVS, Gokhale R. Synthesis and characterization of Ag/PVA nanocomposite by chemical reduction method. Mater. Chem. Phys. 2005;93(1):117-21. https://doi.org/10.1016/j. matchemphys.2005.02.029.

21. Yao N, Lin WJ, Zhang XF, Gu HW, Zhang LJ. Amphiphilic $\beta$-cyclodextrinbased star-like block copolymer unimolecular micelles for facile in situ preparation of gold nanoparticles. J Polym Sci Pol Chem. 2016;54(1):18696. https://doi.org/10.1002/pola.27889.

22. Yenice Z, Schön S, Bildirir H, Genzer J, Klitzing R. Thermoresponsive PDMAEMA Brushes: Effect of Gold Nanoparticle Deposition. J Phys Chem B. 2015;119(32):10348-58. https://doi.org/10.1021/acs.jpcb.5b04757; PMid:26132296.

23. Song LC, Sun H, Chen XL, Han X, Liu HL. From multi-responsive tri-and diblock copolymers to di block-copolymer-decorated gold nanoparticles: the effect of architecture on micellization behaviors in aqueous solutions. Soft matter. 2015;11(24):4830-9. https://doi.org/10.1039/C5SM00859J; PMid:25986926.

24. Mu CD, Liu F, Cheng QS, Li HL, Zhang GZ, Lin W. Collagen cryogel crosslinked by dialdehyde starch. Macromol Mater Eng. 2010;295(2):100-7. https://doi.org/10.1002/mame.200900292.

25. Rainville L, Dorais MC, Boudreau D. Controlled synthesis of low polydispersity $\mathrm{Ag} @ \mathrm{SiO} 2$ core-shell nanoparticles for use in plasmonic applications. RSC Adv. 2013;3(33):13953-60. https://doi.org/10.1039/c3ra41677a.

26. Steigerwald ML, Alivisatos AP, Gibson JM, Harris TD, Kortan R, Muller AJ. Surface derivatization and isolation of semiconductor cluster molecules. J. Am. Chem. Soc. 1988;110(10):3046-50. https://doi.org/10.1021/ja00218a008.

27. Misiuk $W$. Study of the inclusion behaviour of $\beta$-cyclodextrin with ziprasidone and its pharmaceutical application. Int J Pharm Pharm Sci. 2015;7(1):463-6.

28. Budryn G, Zaczyńska D, Rachwał-Rosiak D. Changes in properties of food proteins after interaction with free and $\beta$-cyclodextrin encapsulated hydroxycinnamic acids. Eur Food Res Technol. 2015;240(6):1157-66.; https://doi.org/10.1007/s00217-015-2419-9.

29. Budryn G, Pałecz B, Rachwał-Rosiak D, Oracz J, Belica S. Effect of inclusion of hydroxycinnamic and chlorogenic acids from green coffee bean in $\beta$-cyclodextrin on their interactions with whey, egg white and soy protein isolates. Food Chem. 2015;168:276-87. https://doi.org/10.1016/j. foodchem.2014.07.056; PMid:25172711.

30. Radu CD, Parteni O, Ochiuz L. Applications of cyclodextrins in medical textiles: review. J. Control. Release. 2016;224:146-57. https://doi. org/10.1016/j.jconrel.2015.12.046; PMid:26796039.

31. Wiley B, Herricks T, Sun YG, Xia YN. Polyol synthesis of silver nanoparticles: use of chloride and oxygen to promote the formation of single-crystal, truncated cubes and tetrahedrons. Nano Lett. 2004;4(9):1733-9. https://doi. org/10.1021/nl048912c.

32. Selvam S, Gandhi RR, Suresh J, Gowri S. Antibacterial effect of novel synthesized sulfated $\beta$-cyclodextrin crosslinked cotton fabric and its improved antibacterial activities with $\mathrm{ZnO}, \mathrm{TiO} 2$ and $\mathrm{Ag}$ nanoparticles coating. Int J Pharm. 2012;434(1):366-74. https://doi.org/10.1016/j.ijpharm.2012.04.069; PMid:22627018.

33. Abou-Okeil A, Amr A, Abdel-Mohdy FA. Investigation of silver nanoparticles synthesis using aminated $\beta$-cyclodextrin [J]. Carbohyd Polym. 2012;89(1):1-6. https://doi.org/10.1016/j.carbpol.2012.01.038 ; PMid:24750595.

34. Zhang YW, Peng HS, Huang W, Zhou YF, Yan DY. Facile preparation and characterization of highly antimicrobial colloid Ag or Au nanoparticles. J Colloid Interf Sci. 2008;325(2):371-6. https://doi.org/10.1016/j.jcis.2008.05.063; PMid:18572178. 


\section{PICTORIAL ABSTRACT}

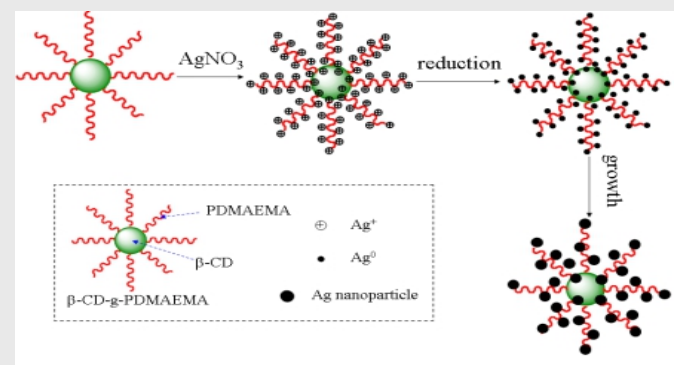

\section{About Authors}

Dr Jianhua Zhou: She is working as a professor in Shaanxi University of Science and Technology. Her main research interests focus on the synthesis of functional polymer materials including nanomaterials modified polymer, star polymer and environment-sensitive polymer, and their application in drug delivery and surface coating. More than 15 research projects have been granted, including National Natural Science Fund of China, Science and Technology Coordinating Innovative Engineering Project of Shaanxi Province. She has 18 years of teaching and research experience which is highlighted in different national and international journals.

Cite this article: Zhou J, Zha X, Chen X, Ma J. $\beta$-Cyclodextrin-g-Poly (2-(dimethylamino) ethyl methacrylate) as the Stabilizer and Reductant to Prepare Colloid Silver Nanoparticles in situ. Indian J of Pharmaceutical Education and Research. 2017;51(4):543-50. 